\title{
The financial market impact of UK quantitative easing ${ }^{1}$
}

\author{
Francis Breedon, ${ }^{2}$ Jagjit S Chadha ${ }^{3}$ and Alex Waters ${ }^{4}$
}

\begin{abstract}
We measure the impact of the UK's initial 2009-10 Quantitative Easing (QE) Programme on bonds and other assets. First, we use a macro-finance yield curve both to create a counterfactual path for bond yields and to estimate the impact of QE directly. Second, we analyse the impact of individual QE operations on a range of asset prices. We find that QE significantly lowered government bond yields through the portfolio balance channel - by around 50 to 100 basis points. We also uncover significant effects of individual operations but limited pass through to other assets.
\end{abstract}

Keywords: Term structure of interest rates, monetary policy, quantitative easing

JEL classifcation: E43, E44, E47, E58

1 This paper forms part of a project to understand unconventional monetary policy. We are grateful for helpful conversations and comments from Luisa Corrado, Alain Durre, Sean Holly, Mike Joyce, Jack Meaning, Mathan Satchi, Katsuyuki Shibayama, James Warren and participants at the BIS-OECD Workshop on Policy Interactions: Fiscal Policy, Monetary Policy and Debt Interaction. Any remaining errors are our own.

2 Queen Mary, University of London. E-mail: f.breedon@qmul.ac.uk.

3 University of Kent, Canterbury, and Centre for International Macroeconomics and Finance, University of Cambridge. E-mail: jsc@kent.ac.uk.

4 School of Economics, University of Kent, Canterbury, Kent. E-mail: aw365@kent.ac.uk. 


\section{Introduction}

Following the financial crisis of 2008, Quantitative Easing (QE) - which we define in this paper as large scale purchases of financial assets in return for Central Bank reserves became a key element of monetary policy for a number of major Central Banks whose interest rates were at, or close to, the zero lower bound. But despite its widespread use, QE remains highly controversial both in terms of its effectiveness and its implementation. Although we now have the benefit of hindsight in the sense that there are a number of QE programmes that can be studied, an empirical assessment of those programmes presents a number of familiar challenges. First, since there is no generally accepted theoretical framework in which to assess QE, empirical studies must either eschew theoretical restrictions that might aid identification or risk having their results dismissed as modelspecific. Second, since QE was not entirely unanticipated, in the sense that it was widely discussed by financial market participants before it was implemented, studies that place a large weight on announcement effects may well give misleading results. Third, since QE was implemented in response to an economic crisis, all the standard economic concerns over endogeneity apply in this case. Finally, since the number of QE-policy shocks is still very limited, conventional empirical techniques that rely on a reasonable sample size cannot easily be implemented in this case.

In this paper, which focuses on the impact of the first UK QE programme (March 2009 to February 2010) on asset prices, we aim to bypass most of these problems through two empirical approaches. First we estimate a macro-finance model of the UK government liability curve which allows us to construct a counterfactual estimate of the term structure over the QE period and, under some strong assumptions, to simulate the impact of QE on the yield curve directly. Second, we look in detail at the liquidity effects of the large sample of individual gilt purchase operations and assess the extent to which these liquidity effects extend beyond the gilt market. We also begin with a more qualitative assessment of the impact of QE on UK monetary aggregates. While not a key element of the paper, this assessment serves as useful background and allows us to link our results from financial markets to monetary quantities such as bank lending.

In the remainder of this section we present a brief (not exhaustive) review of the literature on empirical assessment of QE. Section 2 then presents an overview of the observed impact of UK QE on monetary aggregates. Section 3 introduces our macro-financial yield curve model and the counterfactual path it generates. Section 4 examines operation-by-operation liquidity effects of QE, and Section 5 concludes.

\section{$1.1 \quad$ A brief literature review}

Early work on the impact of large scale asset purchases as a tool of monetary policy probably began following "Operation Twist" in the United States in 1961. Although not full Quantitative Easing in the sense of being financed by base money creation, this operation involved Federal Reserve purchases of long-term bonds (financed by sales of short-term Treasury Bills) as well as a change in Treasury issuance with the aim of lowering long-term interest rates. Modigliani and Sutch (1966) found that this operation had no significant effect on bond yields, though more recent work by Swanson (2011) has found that this operation had some significant market impact. ${ }^{5}$

More recently, the QE programme implemented by the Bank of Japan from 2001 to 2006 generated new interest in unconventional monetary policy implemented through large scale

\footnotetext{
5 Both papers did, however, calculate the point response of medium-term yields at just under 20bp.
} 
asset purchases. In a survey of empirical evidence in the Japanese case, Ugai (2007) found mixed evidence. He concluded that the evidence suggested that QE had some signalling impact on market expectations in the sense of confirming that interest rates would remain low for some time, but that evidence on whether the QE operations had any direct effect on bond yields or risk premia was mixed. However, Bernanke et al (2004), examining the Japanese experience with QE, found little by way of announcement effects but some evidence from a macro-finance yield curve to suggest that Japanese yields were roughly 50bp lower than expected during QE. Unsurprisingly perhaps, the QE programmes implemented in the aftermath of the 2008 financial crisis have led to a dramatic increase in research on this topic. Most notably, the Federal Reserve's QE programme has spawned a large and rapidly growing literature. Important empirical contributions include Doh (2010), D'Amico and King (2010), Gagnon et al (2010), Hamilton and Wu (2010), Neely (2010), Hancock and Passmore (2011), Krishnamurthy and Vissing-Jorgenson (2011) and Wright (2011). In the US case, despite a wide range of methodological approaches, there is nearunanimous agreement that the US programme had significant effects on longer-term bond yields, though estimates of the scale of the effect vary considerably. For example, Gagnon et al (2010) find that the $\$ 300 \mathrm{bn}$ of US bond purchases, which amount to approximately $2 \%$ of GDP, resulted in drops of some 90bp in US 10-year Treasuries, while Krisnamurthy and Vissing-Jorgensen (2010) find that a reduction in public debt outstanding of around $20 \%$ of GDP would reduce yields by between 61 and 115 base points. So far, the UK's QE programme has attracted less interest. Recently released empirical estimates of the impact of the initial $£ 125 \mathrm{bn}$ of QE and then the full £200bn (14\% of GDP) on UK gilt yields by Meier (2009) and then Joyce et al (2010) suggest that yields are some 40-100bp lower than they would have been in the absence of QE. Caglar et al (2011) do, however, suggest that the event study methodology may have overestimated the effects because of the dominant, possibly exaggerated, impact of the first, rather than the subsequent six, announcements. Thus, in this paper we want to make our expectations of the bond price, in the absence of any QE, conditional on the macroeconomic structure, as well as examining the direct impact of actual purchases at each auction.

\section{Quantitative easing and the monetary aggregates}

Although it is not the main focus of this paper, tracing the impact of QE on the narrow and broad monetary aggregates serves as a convenient way of describing QE in the UK case, and furnishes some useful insights into monetary flows associated with QE.

\subsection{QE and the Bank of England's balance sheet}

Although a stated policy of quantitative easing was not implemented until March 2009, a number of prior developments paved the way to full easing. Probably the first important step was the dramatic increase in the size of the Bank of England's balance sheet (see Figure 1), which occurred in September 2008 following the collapse of Lehman Brothers under the Special Liquidity Scheme. This expansion effectively involved providing liquidity to the UK banking system (temporarily acquiring bank assets in return for liquidity, predominantly through reverse repo transactions), but since it was financed by issuing Treasury Bills it did not result in an equal expansion of the monetary base.

In effect, the monetary base provided through repo transactions was re-absorbed through issuance of other financial liabilities, leaving the Bank of England holding risky bank assets financed largely by Treasury Bills. However, it is noteworthy that there was some expansion of the monetary base over this period, as banks - which were allowed to set their own targets (within a certain range) for reserve balances held at the Bank of England - chose to set very high targets (close to the limit, ie $£ 1$ billion or $2 \%$ of their sterling eligible liabilities as set by the Bank of England, whichever was higher) and earn the low but risk-free return that 
the Bank of England pays on reserves. Thus, in some sense a small measure of quantitative easing occurred over this period, since some of the increase in the Bank of England's assets was financed by an unusually large expansion of the monetary base. The voluntary increase in reserve balances over this period is also important evidence that banks were willing holders of low-yielding but safe reserve money, and so were probably not averse to holding even more reserves when full QE was implemented.

The next step was the policy of 'qualitative' easing that was implemented in January/February 2009 following an exchange of letters between the Treasury and the Bank of England (19 January and 29 January). This involved the creation on 30 January of the Asset Purchase Facility (APF), a legally separate entity run by the Bank of England but with indemnity assurances from the Treasury for any possible losses. Initially, the APF operated by buying unsecured corporate commercial paper financed by issuing Treasury Bills. But following a further exchange of letters between the Bank of England and the Treasury (17 February and 3 March), the Monetary Policy Committee (MPC) meeting of 5 March 2009 decided to move to a policy of quantitative easing (QE), with the Bank of England aiming to purchase $£ 75 \mathrm{bn}$ of assets through the APF over the following three months, financed entirely by an expansion of the monetary base. Although the APF continued to purchase corporate debt (expanded to include corporate bonds), the vast majority of purchases were of UK government conventional bonds (gilts) with residual maturity of more than 3 years. In order to facilitate the expansion of the monetary base, the Bank of England suspended both the system of targets and limits on banks' reserve holdings, and pledged to pay the official interest rate of $0.5 \%$ on all bank reserve holdings. The target for asset purchases was then increased to $£ 125$ billion at the May 7th MPC meeting, to $£ 175$ billion at the August 6th meeting and to $£ 200$ billion at the November 5th meeting. At the MPC meeting of 4 February 2010, it was decided not to increase the stock of APF assets any further, and thus QE was effectively temporarily suspended as the programme of asset purchases was by then complete until QE was re-introduced in October $2011 .^{6}$

Figure 2 traces the impact of QE by examining gilt holdings by sector. Prior to the fourth quarter of 2008 the main holders of gilts were UK pension funds and insurance companies, the Overseas Sector and other UK-based non-bank institutions. Following the introduction of QE, the APF quickly became a significant holder of gilts, rising to a peak of about 24 per cent of the total stock (over 13 per cent of GDP) by the end of 2009. However, this dramatic increase in APF holdings had remarkably little impact on gilt holdings by other sectors, since it was more than offset by an increase in the total stock of gilts in issue. Thus, apart from other UK non-bank institutions (such as households and hedge funds), gilts holdings by other sectors continued to rise, albeit at a slow rate. Another interesting aspect of the period since late 2008 is the sudden rise in holdings of gilts by banks. This almost certainly reflected increased regulatory pressure on banks to hold more liquid assets.

\subsection{QE and the broader monetary aggregates}

In the early days of QE, many commentators - arguably including the Bank of England itself (see Financial Times, 2010) - expected the main indicator of QE success to be more rapid growth in the broad monetary aggregates. In this section we look at the qualitative evidence regarding the impact of QE on broad money and lending, as background to a more detailed look at the policy's effect on asset prices.

6 Following the MPC meeting in October 2011, it was announced on 6 October that a further $£ 75$ billion of asset purchases would occur, implying a total stock of $£ 275$ billion of such asset purchases. 
Overall, broad money (deposit) growth over the QE period was weak. Figure 3 shows both the level of the Bank of England's favoured measure of broad money, M4x (standard M4 less intermediate other financial corporations, or OFCs) and the year-on-year growth rate. Immediately following the introduction of QE, the growth rate of M4x continued to fall, to just under $1 \%$ at the end of 2009 , and stayed considerably below the Bank's 6-8\% target range through 2010. Although this low rate of growth seems at odds with the idea that QE should boost bank lending, there may be a number of explanations. First, without QE, and given the state of demand, there might easily have been even weaker growth, if not a significant contraction of broad money. Secondly, there was a significant level of new debt and equity issuance by the UK banking sector over this period, as it aimed to recapitalise (see Figure 6). Such issuance will tend to reduce M4x growth for a given level of lending in the banking sector, as it increases non-deposit liabilities (so new lending can be funded without increasing deposits). A measure of the downward pressure on the money supply caused by this recapitalisation of UK banks is captured by net non-deposit liabilities. ${ }^{7}$ Over the QE period, the cumulative total creation of these liabilities was approximately $£ 242 \mathrm{bn}$, suggesting a substantial undermining of the impact the monetary boost might have had on the money supply.

If we focus on the lending side of banks balances, however, the picture is similar to M4 deposits. Overall, total M4 lending excluding securitisations and loan transfers (M4LX) fell over the QE period by $£ 197.5 \mathrm{bn}$. This reflects an increase in bank holdings of other assets such as central bank reserves (see Figure 1) and gilts (see Figure 2). Breaking down lending by sector, Figure 4 shows that there was some recovery in lending to households over the QE period (reaching around 3\% growth at the end of 2009, and continuing into 2010), after a contraction in the 12 months following the collapse of Lehman Brothers. However, lending to Private Non-Financial Companies (PNFCs) showed no such recovery. The largest contraction in lending was in May 2010, with a year-on-year contraction of $4.2 \%$, and there was little sign of improvement thereafter.

The low overall rate of money growth is at odds with data from the Bank of England survey on credit conditions. Figure 5 plots the response of corporates to the question "How has the availability of credit provided to the corporate sector overall changed?" 8 In Figure 5, the blue bars show the response over the past three months, and the red line shows the expectations over the next three months. The expected balance is moved forward one quarter so that expectations can be compared to the actual outturn in the following quarter. Prior to QE, the availability of credit declined, and it did not show much improvement until QE commenced. The survey response is further disaggregated into different factors, and it appears that the key factor driving the improvement was the changing cost and availability of funds, followed by the increasing availability of loans in the market. Both of these factors suggest that QE was affecting the loan supply.

7 The non-deposit liabilities (net) category consists of capital and other non-deposit liabilities of UK banks less their investments in UK banks and other non-financial assets. In the Bank of England series used (series code LPMVRHV), a negative value indicates an increase in non-deposit liabilities and downward pressure on broad money.

8 The response to these questions is presented in the Bank of England's Credit Conditions Survey, which is conducted monthly, with results published quarterly. The survey asks lenders a series of questions to identify trends and developments in credit conditions over the past three months, and to ascertain their expectations for the coming three months. All lending is from UK-based institutions, but it includes both sterling lending and foreign-currency-denominated lending. The survey does not solicit information about capital issuance by the lenders, but asks about available supply and demand conditions. The information here comes from the Bank of England's Credit Conditions Survey for the 3rd Quarter of 2011, Annex 3: Corporate Lending Questionnaire Results. 
In fact it appears that firms' confidence in the availability of funds was expressed in a decision to bypass the banking system altogether and issue capital directly. Figure 6 shows net capital issuance by PNFCs. ${ }^{9}$ This consists of UK-based primary-market issuance of bonds, commercial paper and equity financing in both domestic and foreign currencies by entities domiciled in the UK. ${ }^{10}$ Specifically, the majority of assets issued over the QE period by PNFCs were bonds, with shares in second place. The net issuance of commercial paper was generally negative. Overall, there is some evidence that PNFCs stepped up their net capital issuance during the QE period, and although this may simply reffect continuing problems with bank financing, the fact that credit conditions were seen to have improved suggests that it may have been motivated by a desire to tap capital markets flush with the proceeds of gilt sales to the QE programme.

To summarise, the period covered by the Bank of England's asset purchase programme can be described as one of low but positive growth in deposits, counteracted by heavy debt and equity issuance in the corporate sector, and to some degree in the financial sector. Overall, although monetary aggregates or their counterparties show little improvement over the QE period, suggesting little clear expansion by the banking sector, corporates seemed to have responded to QE by issuing capital directly.

\section{QE and the yield curve}

As we have seen in the previous section, a fundamental problem in assessing the impact of QE on the monetary sector is to define the appropriate counterfactual. In this section we attempt to estimate such a counterfactual for the nominal gilt yield curve, to assess whether yields were significantly influenced by QE. Our approach is to estimate a simple term structure model driven by several macroeconomic factors. This model is then used to estimate a predicted yield curve over the QE period, and so the difference between the predicted and actual yield curve over this period can be interpreted as an estimate of the portfolio-balance impact of QE, since QE itself is not included as a factor. Of course any macro impact of QE should be reflected in the macro factors that drive our yield curve model, so this exercise can only identify the extent to which large-scale purchases shifted the yield curve directly. This approach, which is similar to that used by Bernanke, Reinhart and Sack (2004), can be thought of as a sophisticated event study where the market model is our macro term structure model. As well as a counterfactual approach, we use some admittedly ad hoc assumptions to identify the impact of QE using the estimated parameters of our model, providing an alternative route for estimating the portfolio-balance effect of QE. Both approaches have the advantage of allowing us to estimate the longer-term impact of QE, not simply high-frequency announcement effects.

9 The data are available in the Bank of England's Bankstats, Table 3.1. There are also data for building societies (B63M) and resident banks (B32M). The data here go through 2009 only. They are not plotted, but are available on request. The codes for the data in the order presented in Figure 5 are B83I, B79I and B82I.

10 The bonds issued are not part of any specific programme, and represent assets that will have an ongoing series of issues. The commercial paper issued include maturities up to and including one year. The shares consist of both preferred and ordinary shares making up the firm's share capital. Shares can also be bought back for the purpose of being cancelled, or to be held in treasury. Net capital issuance is the difference between issuance and repayments for the three financial instruments. 


\subsection{A benchmark term structure model}

Our macro-finance term structure model is estimated in two stages. The first stage involves putting the term structure into the functional form proposed by Svensson (1994). We employ an approach similar to that of Diebold et al (2006) and Afonso and Martins (2010), obtaining the four latent factors - level, slope and two curvatures - by means of the Kalman filter. The second step is to relate these latent factors to a representative set of macroeconomic variables through a SUR regression.

The functional form proposed by Svensson is:

$$
y(\tau)=\beta_{1}+\beta_{2}\left(\frac{1-e^{-\tau \lambda_{1}}}{\tau \lambda_{1}}\right)+\beta_{3}\left(\frac{1-e^{-\tau \lambda_{1}}}{\tau \lambda_{1}}-e^{-\tau \lambda_{1}}\right)+\beta_{4}\left(\frac{1-e^{-\tau \lambda_{2}}}{\tau \lambda_{2}}-e^{-\tau \lambda_{2}}\right)
$$

This factor model approach expresses a large number of yields of various maturities as a function of a few unobserved factors. The yield is denoted as $y(\tau)$, where $\tau$ denotes the maturity and $\beta_{1}, \beta_{2}, \beta_{3}, \beta_{4}, \lambda_{1}$ and $\lambda_{2}$ are parameters. The parameters $\lambda_{1}$ and $\lambda_{2}$ govern the rate of exponential decay. The smaller the value of lambda, the slower the decay and the greater the fit at the longer maturities; the larger the value of lambda, the faster the decay and the greater the capacity of the fit at shorter maturities. The lambda is also used to determine the maximum loading of $\beta_{3}$ and $\beta_{4}$. The parameters $\beta_{1}, \beta_{2}, \beta_{3}$ and $\beta_{4}$ are the parameters which correspond to the appropriate factor loadings. The loading on $\beta_{1}$ is 1 . Termed the level, it is constant and can be seen as a long-term factor. Any shift in it will have an equal effect across all yields. The factor loading of $\beta_{2}$ has a functional form that starts at 1 but decays monotonically and quickly to 0 . It is considered a short-term factor and is called the slope factor. Any change in $\beta_{2}$ will have a greater effect on the short-term yields than on the longer-term ones, thereby changing the slope of the yield curve. The final two factors, $\beta_{3}$ and $\beta_{4}$, have loadings that begin at 0 , so they are not short-term. However, they increase and then decay back to zero, so they cannot be long-term either. This type of factor is a medium-term factor and is termed the curvature. Any changes in $\beta_{3}$ and $\beta_{4}$ will have very little effect on either the short or long end of the yield curve, as the yield curve has very little loading on these maturities. Hence, any increase in these factors will increase medium-term yields and consequently increase the curvature of the yield curve. Therefore, the Svensson representation can now be interpreted as a dynamic latent factor model where $\beta_{1}, \beta_{2}, \beta_{3}$ and $\beta_{4}$ become time-varying parameters that capture the level $(L)$, slope $(S)$, first curvature factor $\left(C_{1}\right)$ and second curvature factor $\left(C_{2}\right)$ of the yield curve at time $t$.

Like Diebold et al (2006) and Afonso and Martins (2010), we assume that $L_{t}, S_{t}, C_{1, t}$ and $C_{2, t}$ follow a first-order vector autoregressive process which allows the model to form a statespace system. The Kalman filter is then used to obtain maximum-likelihood estimates of the parameters and the implied estimates of $L_{t}, S_{t}, C_{1, t}$ and $C_{2, t}$. This estimation is performed for the nominal curve, and estimation details are available on request.

In order to relate these factors to macroeconomic variables we estimate a SUR model of the following general form:

$Y_{t}=\alpha+\rho Y_{t-1}+\beta X_{t}+d \delta+\varepsilon_{t}$

$Y$ is a $4 \times 1$ vector of dependent variables (the level, slope and curvature factors identified above), $\alpha$ is the vector of constants, $\rho$ is a vector of coefficients for the lagged dependent variables and $\beta$ is a matrix of coefficients of the independent variables $X_{t}$. The final equations have been determined by a general-to-specific approach performed 
simultaneously across all four equations. The analysis of the coefficients and their significance is taken a step further after estimation. We test exclusion restrictions on each one of the four coefficients from each equation for each macroeconomic variable, and assess whether it could have been excluded from the system (see Table 1). The standard estimator for SUR is feasible generalised least squares (FGLS). We use FGLS, as we do not know the true variance-covariance matrix. Using the SUR estimator with the information in the system of equations is more efficient than using an estimator on individual equations. FGLS is preferable to OLS for two reasons: the more correlation there is between the residuals, the greater the efficiency gain attributed to FGLS; and the less correlation there is between the $X_{t}$ matrices, the greater the gain to FGLS.

\subsubsection{Data}

We fit the nominal term structure using maturities of $9,12,15,18,21,24,30,36,48,60,72$, 84, 96, 108 and months for the zero coupon forward curve ${ }^{11}$ at a monthly frequency between March 1993 and December 2008. The macroeconomic variables are divided into 5 groups - inflation, real activity, policy, foreign and financial - and tested down from over 30 variables. For inflation we use inflation expectations, which is the average one-yearahead inflation forecast from HM Treasury. ${ }^{12}$ Real activity is represented by two variables, a real activity index and unemployment. For policy, we include the Bank of England's monetary policy interest rate; for our measure of the net supply of bonds we use the debt-to-GDP ratio; and to measure duration effects we use the ratio of long term bonds ( $>15$ years residual maturity) to nominal debt outstanding. Unfortunately, more precise measures of the duration of government debt were not available over the whole sample. For foreign variables we include the effective exchange rate, German retail sales, the IFO index of business climate, US Non-Farm Payrolls expressed as year-on-year changes, and the Fed Funds Rate. The final group of macroeconomic variables is the financial group. For this we use an index of the annual returns of three different equity series, and a measure of the Libor spread, which is the difference of the three-month Libor and the monetary policy rate of the Bank of England. Normally, the Libor spread is the difference between the 3-month Libor and Overnight Interest Rate Swaps, but as the OIS data do not go back to 1993 we use the policy interest rate as a proxy. Under the financial group of variables we also include a measure of real money. ${ }^{13}$

We create an index of real activity using principal component analysis from three different measures of real activity: UK production, UK retail sales and the claimant count. These variables were recast as year-on-year change before the first principal component was extracted. We also create an index of financial returns by taking the annual returns of three different equity series: the Standard and Poors 500, the DAX 30 and the FTSE 100. As in the case of the real activity index, we use the first principal component of the three series. We also include time trends.

The descriptive statistics of this model are given in Table 2. The $R^{2} s$ are high across all four of the equations, for the level and slope equations in particular, but the two curvature factors

11 The estimates for the yields are derived with a cubic spline technique. See Anderson and Sleath (1999).

12 For further information, we refer the reader to "Forecasts for the UK Economy: a Comparison of Independent Forecasts".

13 The measure of real money is the Bank of England's notes and coin in circulation (series code LP-MAVAB) deflated by RPI. Notes and coin is used to represent narrow money. M0 was the Bank's main narrow money measure. When the Bank introduced its Money Market Reform in May 2006, the Bank ceased publication of $\mathrm{MO}$ and instead began publishing a series for reserve balances to accompany notes and coin in circulation. Notes and coin is the longest available measure of narrow money. 
do less well. As occurs in the other macro-finance literature, we struggle to find a better macroeconomic explanation for the curvature factors. These results are corroborated by analysis of root-mean-square errors, with the resulting errors being smaller for the very well explained level and slope. The tests for autocorrelation, heteroscedasticity and normality show that the residuals do not suffer from autocorrelation at one or five per cent. Heteroscedasticity is not a problem in the residuals either. The only problem that is apparent is normality. For the level and the second curvature factors we reject the null hypothesis that the errors are normally distributed at both one and five per cent We also reject the null hypothesis at five per cent for the slope, but this is a more satisfactory result. It is only the first curvature factor where we accept the null hypothesis at both one and five per cent. ADF tests (not presented) confirm that the forward curve factors are stationary.

\subsubsection{Impulse responses}

Figure 7 shows the estimated responses of the nominal forwards to $1 \%$ shocks in the final set of variables used to fit the term structure. The dotted lines represent one standard deviation on either side. Rather than discuss each impulse response we draw attention to one simple example: that a permanent $1 \%$ shock to inflation expectations raises nominal forwards by $1 \%$ at the ten-year horizon. In terms of the possible impact of QE, we find that the net public debt-to-GDP ratio has a small upward impact on forwards of between 3 and 9 basis points for each 1\% of held as a fraction of GDP. A reduction of debt amounting to just under $25 \%$ of GDP might therefore have an effect of some 75 to $225 \mathrm{bp}$ on yields (depending on maturity). We also find that the effect of a $1 \%$ increase in the fraction of long term bonds outstanding is to increase 5 -year yields and beyond by some 13-15bp. We use these results in the simulation below, in which we interpret QE as reducing net debt outstanding and also as changing the duration of that debt.

\subsection{An assessment of QE through a macro term structure model}

In this section we assess the pure portfolio-balance impact of QE using our term structure model. (As noted above, any macro impact of QE should feed through the macro drivers of our model). We do this in two ways. First, we create a dynamic forecast of the yield curve using our macro factors to estimate the impact of QE under the assumption that QE is a key driver of prediction errors over this period (ie that QE is responsible for a portfolio-balance effect that causes the curve to deviate from its predicted level). Second, through a number of assumptions, we identify QE with parameters of the model itself and so undertake a simulation of the impact of QE on the term structure. Both approaches have their drawbacks, but it is somewhat reassuring that they deliver similar estimates.

\subsubsection{QE counterfactual}

To construct a counterfactual path for bond yields (ie one that does not include the portfoliobalance effects of QE), we simply project a path for the term structure using the model described above and using the actual outturns for the macro variables as the only inputs. Our projection starts in January 2009 and continues over the whole QE period. The 1-, 5- and 10-year fitted forward rates and forecast errors are shown in Figure 8 . We find that the model generally overpredicts the actual forward curves observed from around March onwards, at horizons longer than approximately 24 months. This overprediction averages $67 \mathrm{bp}$ at the 5-year maturity, and 46bp at the 10-year, over the period in which QE operated. This result is consistent with a QE portfolio-balance effect in timing, direction and duration (in the sense that only yields above the 2-year maturity level seem affected, that yields are lower than predicted and that the overprediction kicks in precisely when QE was announced and implemented). There is also little evidence of a pre-announcement effect, in that the fall in bond yields seems to have occurred in March when the programme was announced. In fact, in the two months prior to the QE operations, the model underpredicts the medium- to longend of the term structure by some $45 \mathrm{bp}$ on average at 5 years, and by $80 \mathrm{bp}$ at the 10-year 
horizon $^{14}$. One explanation for this underprediction before QE may be that there were heightened concerns over UK solvency over those two months. Thus, although our model includes the debt-to-GDP ratio as a factor, it is unlikely to capture these solvency concerns, for reasons we discuss below.

Figure 9 shows the behaviour of UK Government Credit Default Swaps (CDS) over this period. It shows that there was indeed a large spike in perceived default risk just prior to QE and a significant decline as QE was implemented. If we adjust bond yields for this CDS effect we find that the model's underprediction in January and February is more than explained by this credit risk effect, and indeed some - though not all - of the drop in yields that occurred subsequently was associated with reduced credit risk. Of course one might reasonably argue that QE was the cause of the fall in perceived credit risk that occurred around March 2009, though we cannot test this proposition using our model.

\subsubsection{QE simulation}

Although our counterfactual path gives an intuitively appealing estimate of the QE effect, it is hardly definitive. Firstly the difference between the actual and predicted path of forward rates is not statistically significant according to our standard errors. Second, one might reasonably argue that so much was going on over this period that the difference between the two paths could be explained by any number of factors not captured in our model, not solely by QE. Thus, in this section we take a different approach to estimating the QE effect, simulating the estimated effect of QE using the estimated parameters of our model.

In order to do so, we need to make a number of assumptions that allow us to proxy QE with factors that drive our model.

1) We assume that the variable debt-to-GDP captures a pure supply effect on the yield curve, and not other factors like credit risk (since a high debt-to-GDP increases the perceived likelihood of default). This assumption can be partially justified by observing that perceived credit risk was insignificant over almost all of the model's estimation period (apart from the last few months).

2) Given our first assumption, we then assume that a reduction in the supply of gilts available to the private sector through QE has the same impact as an equivalent reduction in the overall debt-to-GDP ratio. These two assumptions then mean that we can interpret the overall impact of QE as a reduction in the debt-to-GDP ratio.

3) In a similar way, we assume that our duration variable captures a pure supply effect on long-duration debt, and hence can be used to capture the impact of a change in the average duration of debt available to the private sector due to the pattern of purchases associated with QE.

4) Finally, we make the assumption that the reduced debt-to-GDP effect of QE occurred when details of the amount to be purchased were announced, while the duration effect occurred when debt purchases were implemented (since market participants would not know the precise duration breakdown of QE purchases until a few weeks before they were implemented).

Given these assumptions, we can directly estimate the impact of QE on bond yields as the the total reduction in the supply of gilts available to the private sector, combined with the change in the average duration of the remaining gilts attributable to QE. As noted above, we assume the debt-to-GDP effect occurred when the amount to be purchased was announced

14 The forecast errors and standard deviations by maturity for each month of Quantitative Easing are available upon request. 
at each MPC meeting ( $£ 75 \mathrm{bn}$ in March, $£ 50 \mathrm{bn}$ in May, $£ 50 \mathrm{bn}$ in August and $£ 25 \mathrm{bn}$ in November). Following the March announcement, the amount of purchases led to a $5.35 \%$ drop in the debt-to-GDP ratio, and at the end of the QE purchases the figure was $14 \%$ of GDP.

To calculate the duration effect we use the estimated duration parameter from our yield curve model. This can be seen in the impulse response shown in Figure 7, which is based on the share of long-dated gilts ( $>15$ years residual maturity) relative to the total stock of nominal bonds. To calculate the effect that QE had on the duration of the portfolio we determine the amount of long bonds and the total amount of nominal in issue. We measure the amount of long-term bonds purchased in the reverse auctions, and subtract this from the total amount of long-term bonds already in issue. Then we divide this amount by the total portfolio of nominal bonds minus total QE purchases. The difference between the two series (long-term bonds as a share of the total, relative to long-term bonds as a share of the total after adjusting for QE purchases) shows that the duration of debt according to our measure actually rose initially as a result of QE, since QE operations were initially focussed on bonds of 5- to 15-year residual maturity. However, around July 2009 operations in long-dated bonds increased significantly, so that the average duration of outstanding debt began to fall (see Figure 1). This pattern means that for much of the QE period the duration effect actually led to higher, not lower, longer-term yields.

Table 3 displays these effects in detail for 5- and 10-year forward rates, showing how the debt-to-GDP effect of QE rose steadily over the period as the amounts to be purchased increased. The duration effect initially offset the debt-to-GDP effect to a degree, as the average duration of remaining debt rose somewhat and then fell again. It is interesting to compare the predicted QE effect from our simulation with the prediction errors described in the previous subsection. Over the whole QE period, the average QE effect predicted by our simulation was to reduce 5-year forward rates by 63 basis points, while the model's overprediction was $67 \mathrm{bp}$ on average. The corresponding figures for 10 -year forwards were $87 \mathrm{bp}$ and 45bp. Similarly, the peak impact of QE according to our simulation was $111 \mathrm{bp}$ and $136 \mathrm{bp}$ for 5- and 10-year forwards respectively, while the model's overprediction was 110bp and $99 \mathrm{bp}$ for those maturities. Thus, the two approaches give reassuringly similar results.

\section{Liquidity effects of individual operations}

Having estimated the long-range effect of the whole QE programme on the yield curve, we now turn our attention to higher-frequency (daily) estimates of the impact of individual QE operations. Looking at individual QE operations has two significant advantages over examining the overall QE effect described above. First, the sample of operations is large, and so standard statistical techniques have some power. Second, these operations were, of course, entirely anticipated, and so any effect we find is entirely due to liquidity. In this section we look at the market impact of these operations to assess the extent to which they produced a pure liquidity effect in the gilt market and other markets. This not only allows us to confirm that QE did indeed influence the bond market, but gives us an opportunity to test whether QE influenced other asset prices. Of course, it is quite possible that the entire market impact of QE occurs through announcement effects rather than through actual implementation, as market participants perhaps position themselves in preparation for absorbing the previously announced market operation. In fact, some studies - such as Beneish and Whaley (1996) in the case of changes in the S\&P index, and Hau, Massa and Peress (2010) in the case of the MSCl-Global index - have found price reversals at the implementation date, meaning that the market impact of an announcement is reversed at implementation (as implied in the market maxim "Buy the rumour, sell the fact"). In our case, however, we do indeed find a significant market impact, with bond prices rising before each 
QE operation and then falling back subsequently, as might be expected if liquidity effects are important.

To estimate the magnitude of the liquidity effect of QE operations we turn to a simple event study. Overall, while there are 576 individual bond purchase operations in our sample, these operations tended to be grouped together on a single day, with the actual gilts eligible for each operation being announced the previous week (though by looking at previous operations, market participants would have been able to make a well-educated guess as to which gilts would be eligible). In practice, we treat a group of operations on a single day as a single operation, giving us a sample of 92 events (taking the average impact across all the gilts purchased in the operation occurring on a particular day). We then look at daily movements in bond prices, using end-of-day midquote data supplied by the UK Debt Management Office in connection with these QE operations. We use prices rather than yields in this analysis, as they form a natural starting point from which to look at other assets such as equities and the exchange rate. In our first analysis, which focuses purely on bonds eligible for the relevant operation, we look at price movements relative to two benchmarks. First, a simple "no change" scenario, so that the significance of price movements around QE operations is judged against the hypothesis that prices should on average be unchanged across the whole event window. Second, we construct a counterfactual daily path for bond prices based on a linearly interpolated prediction from the yield-curve model described above. This effectively helps control for any trend in prices over the event window that are due to underlying macroeconomic developments, and is analogous to the use of a market model in conventional event studies.

Table 4 summarises the results of these event studies. It shows a significant operation-day effect (column t) whereby the price accepted at the QE operation is more than 0.1 per cent higher than the average price at the end of the operation day. Looking at model 2 in particular, there also seems to be a steady upward move in price in the 15 days before the operation, followed by an offsetting decline in the 15 days after the operation, with prices rising about 0.6 per cent in the run up to the operation (relative to the price accepted in the operation) and then falling about 0.6 per cent (as shown in Figure 10). At first sight, the length of time over which this price effect occurs may seem surprisingly long. However, given the relatively low level of turnover in non-benchmark bonds and the opacity of pricing in the gilt market (see, for example, Nath, 2004), slow price responses are often observed in this market. In particular, the pattern we see here is very similar (though of opposite sign) to the path of bond prices in the period around a bond auction (see Ahmad and Steeley, 2007).

Given the likely heteroscedasticity in both price and yield responses to QE operations, we test for the significance of these liquidity effects using a non-parametric Wilcoxon test. The results show that when using the average price accepted in the operation as a benchmark, these liquidity effects are highly significant, particularly in the period after the operation. However, relative to the price at the end of the operation day, the effects are somewhat less significant, and though significance at conventional levels occurs at a number of horizons, it does not occur as consistently.

Since Table 5 shows a generally significant liquidity effect on gilts selected for QE operations, it is interesting to see whether this effect is also observable in other bonds, and indeed in other asset prices. Bearing in mind a large number of caveats (not least of which is that liquidity effects may not influence other asset prices in the same way as the overall impact of QE), such an exercise does perhaps give us some insight into the extent to which QE influences financial markets in general rather than just government bonds. Table 5 shows the behaviour of the rest of the government bond market (based on average prices of bonds in each maturity range as calculated by the Financial Times) and other asset prices around these operations. In all cases the table compares prices at various time horizons with prices at the end of a QE operation date. Starting with the gilt market, it shows that, apart from the 0- to 5-year sector, QE operations seem to have an impact on the average price of bonds (including those not purchased in the QE operation) in the sense that there are significant 
price different relative to the day of a QE operation on at least one time horizon. This impact seems to carry through to 10-year corporate bonds (both AA and BBB) as well as swaps, where the price impact of these operations is comparable with the impact on the 10-year sector of the gilt market. The impact on 10-year OIS is weaker, but this is probably related to the low liquidity of such a long-dated overnight interest-rate swap. Turning to the exchange rate and equity prices, however, we find little discernible QE effect. In the case of the equity market this seems to suggest that the reduction in duration risk associated with QE did not feed through to other long-duration assets like equity. Overall, these results suggest that the liquidity effect of QE was felt across the whole bond market, but did not spread beyond that market. However, such a conclusion is clearly tentative.

\section{Conclusion}

Quantitative easing has become an important monetary policy tool in many countries over recent years, but its effectiveness is still open to considerable doubt. In this study we have taken several approaches to assessing the financial market impact of QE, and in all cases have found it to have a significant and economically important impact on the bond market. In fact, along with the growing body of evidence for the US, it seems that our evidence is contributing to a growing consensus that $\mathrm{QE}$ is indeed effective in terms of influencing longer-term bond yields through a portfolio-balance effect. However, the broader impact of QE on other assets and on the economy in general remains controversial, as our qualitative description of the impact of QE on monetary aggregates confirms. Certainly, that fact that QE was implemented during a credit crunch - a period when even conventional monetary policy has uncertain effects - probably means that this broader question is likely to remain unresolved for some time. 


\section{Tables}

Table 1

\section{Exclusion restrictions tests on the estimated term structure model}

\begin{tabular}{lc}
\hline \hline \multicolumn{1}{l}{ Exclusion restrictions within equations } \\
\hline \hline Level & 5798.85 \\
Slope & {$[0.0000] * *$} \\
Curv. 1 & 5462.55 \\
& {$[0.0000] * *$} \\
Curv. 2 & 1628.32 \\
& {$[0.0000] * *$} \\
Exclusion restrictions across equations \\
\hline \hline Inf. Exp. & 772.02 \\
& 10.27 \\
Real Activity & {$[0.0059] * *$} \\
& 12.75 \\
BoE Policy Rate & {$[0.0004] * *$} \\
& 68.67 \\
Debt to GDP & {$[0.0000] * *$} \\
& 10.33 \\
UK Eff. ER & {$[0.0013] * *$} \\
& 32.84 \\
IFO & {$[0.0000] * *$} \\
& 12.59 \\
German Retail Sales & {$[0.0004] * *$} \\
& {$[0.00 .34$} \\
$\left(\frac{M}{P}\right)$ & {$[0.000] * *$} \\
Libor & 19.71 \\
Duration & {$[0.0000] * *$} \\
& 4.96 \\
\hline \hline
\end{tabular}

Note: This table represents tests for the exclusion of variables within and across equations, and only includes those variables used in the final specification. All tests are chi ${ }^{2}$ with four degrees of freedom. 
Table 2

\section{Descriptive statistics for estimated term structure model}

\begin{tabular}{lcccc}
\hline \hline \multicolumn{5}{c}{ Factor } \\
& Level & Slope & Curv.1 & Curv.2 \\
\hline \hline $\mathrm{R}^{2}$ & 0.950 & 0.954 & 0.863 & 0.725 \\
RMSE & 0.490 & 0.531 & 1.141 & 1.866 \\
Durbin-Alt & 0.020 & 0.307 & 0.760 & 4.835 \\
& {$[0.8865]$} & {$[0.5798]$} & {$[0.3834]$} & {$[0.0279] *$} \\
Breusch-Pagan & 2.98 & 1.63 & 1.48 & 6.56 \\
& {$[0.0844]$} & {$[0.2018]$} & {$[0.2238]$} & {$[0.0104] *$} \\
Normality & 19.085 & 6.2886 & 0.62410 & 39.278 \\
& {$[0.0000] * *$} & {$[0.0162] *$} & {$[0.7319]$} & {$[0.0000] * *$} \\
\hline \hline
\end{tabular}

Note: The Durbin-Alternative test (with one lag), with the null hypothesis that the errors are homoscedastic, with one degree of freedom. The Breusch-Pagan test also has one degree of freedom, and the null hypothesis is that there is no autocorrelation. The normality test has two degrees of freedom, and the null hypothesis is that the errors are normally distributed. All tests have a chi ${ }^{2}$ distribution and ${ }^{\star \star}$ represent rejection of the null at the $1 \%$ level and *represent rejection of the null at the $5 \%$ level.

Table 3

Estimates of the impact of QE on 5- and 10-year forward rates

(in basis points)

\begin{tabular}{|c|c|c|c|c|c|c|c|c|}
\hline & 5 Year Forward & & & & 10 Year Forward & & & \\
\hline & Counterfactual. & Simulation. & & & Counterfactual. & Simulation & & \\
\hline & Prediction error. & Debt effect & Duration effect & Total. & Prediction error. & Debt effect & Duration effect & Total \\
\hline Feb '09 & 35 & 0 & 0 & 0 & 104 & 0 & 0 & 0 \\
\hline Mar '09 & -99 & -37 & 3 & -34 & -50 & -48 & 2 & -46 \\
\hline Apr ' 09 & -47 & -37 & 14 & -23 & -7 & -48 & 11 & -37 \\
\hline May '09 & -18 & -62 & 21 & -41 & 50 & -80 & 16 & -64 \\
\hline Jun '09 & -54 & -62 & 27 & -35 & -35 & -80 & 21 & -59 \\
\hline Jul'09 & -38 & -62 & 35 & -27 & -47 & -80 & 27 & -53 \\
\hline Aug '09 & -75 & -87 & 26 & -61 & -70 & -112 & 20 & -92 \\
\hline Sept '09 & -110 & -87 & 7 & -80 & -99 & -112 & 6 & -106 \\
\hline Oct '09 & -65 & -87 & 0 & -87 & -57 & -112 & 0 & -112 \\
\hline Nov' 09 & -91 & -98 & 4 & -94 & -87 & -126 & 3 & -123 \\
\hline Dec '09 & -67 & -98 & 2 & -96 & -50 & -126 & 2 & -124 \\
\hline Jan '10 & -73 & -98 & -13 & -111 & -54 & -126 & -10 & -136 \\
\hline
\end{tabular}

Note: Prediction error is actual minus predicted path of yield, as described in subsection 3.2.1. Debt and Duration effects are the estimated impact of QE through reduced overall debt and changes in the duration of remaining debt available to the private sector, as described in subsection 3.2.2. Total is simply the sum of debt and duration effects. 
Table 4

Bond prices around QE operations

\begin{tabular}{lllllllllll}
\hline \hline & $\mathrm{t}-15$ & $\mathrm{t}-10$ & $\mathrm{t}-5$ & $\mathrm{t}$ & $\mathrm{t}+1$ & $\mathrm{t}+5$ & $\mathrm{t}+10$ & $\mathrm{t}+15$ & $\mathrm{t}+20$ \\
\hline \hline Model 1: 'No Change' & & & & & & & & & & \\
Relative to operation price & -0.38 & -0.32 & -0.21 & -0.12 & -0.21 & -0.43 & -0.63 & -0.85 & -0.84 \\
& {$[0.33]$} & {$[0.09]$} & {$[0.12]$} & {$[0.01]$} & {$[0.09]$} & {$[0.03]$} & {$[0.00]$} & {$[0.00]$} & {$[0.00]$} \\
& -0.26 & -0.20 & -0.09 & & -0.08 & -0.31 & -0.51 & -0.73 & -0.71 \\
Relative to end-day price & {$[0.39]$} & {$[0.26]$} & {$[0.26]$} & & {$[0.27]$} & {$[0.09]$} & {$[0.06]$} & {$[0.01]$} & {$[0.00]$} \\
& & & & & & & & & \\
Model 2: Interpolated Model & & & & & & & & & \\
Relative to operation price & -0.56 & -0.44 & -0.27 & -0.12 & -0.20 & -0.37 & -0.51 & -0.67 & -0.60 \\
& {$[0.14]$} & {$[0.06]$} & {$[0.04]$} & {$[0.01]$} & {$[0.09]$} & {$[0.06]$} & {$[0.00]$} & {$[0.01]$} & {$[0.01]$} \\
Relative to end-day price & -0.44 & -0.33 & -0.15 & & -0.08 & -0.25 & -0.39 & -0.55 & -0.48 \\
& {$[0.20]$} & {$[0.12]$} & {$[0.21]$} & & {$[0.27]$} & {$[0.14]$} & {$[0.06]$} & {$[0.14]$} & {$[0.03]$} \\
\hline \hline
\end{tabular}

Note: The table presents average price differential (per cent) between either the average price accepted in the QE operation or the price at the end of the operation day, and the price at various horizons. In the case of model 2 the price differential is adjusted for the predicted movement in prices from an interpolated version of the yield curve model described above. Figures in square brackets represent the probability that the price differential is zero, based on the two-sided Wilcoxon Rank Test. 
Table 5

Asset price movements around QE operations

\begin{tabular}{lllllllll}
\hline \hline & $\mathrm{t}-15$ & $\mathrm{t}-10$ & $\mathrm{t}-5$ & $\mathrm{t}+1$ & $\mathrm{t}+5$ & $\mathrm{t}+10$ & $\mathrm{t}+15$ & $\mathrm{t}+20$ \\
\hline \hline APF Gilts & -0.44 & -0.33 & -0.15 & -0.08 & -0.25 & -0.39 & -0.55 & -0.48 \\
& {$[0.20]$} & {$[0.12]$} & {$[0.21]$} & {$[0.27]$} & {$[0.14]$} & {$[0.06]$} & {$[0.14]$} & {$[0.03]$} \\
Gilts 0-5 years & -0.19 & -0.12 & -0.07 & -0.01 & 0.04 & 0.08 & 0.12 & 0.19 \\
& {$[0.21]$} & {$[0.33]$} & {$[0.21]$} & {$[0.39]$} & {$[0.79]$} & {$[0.46]$} & {$[0.61]$} & {$[0.54]$} \\
Gilts 5-10 years & -0.24 & -0.15 & -0.08 & -0.04 & -0.07 & -0.17 & -0.22 & -0.20 \\
& {$[0.12]$} & {$[0.79]$} & {$[0.39]$} & {$[0.06]$} & {$[0.12]$} & {$[0.00]$} & {$[0.12]$} & {$[0.03]$} \\
Gilts 10-15 years & -0.25 & -0.16 & -0.10 & -0.05 & -0.10 & -0.26 & -0.36 & -0.36 \\
& {$[0.09]$} & {$[0.61]$} & {$[0.39]$} & {$[0.21]$} & {$[0.16]$} & {$[0.02]$} & {$[0.09]$} & {$[0.01]$} \\
Gilts 15-25 years & -0.58 & -0.35 & -0.18 & -0.06 & -0.18 & -0.43 & -0.53 & -0.52 \\
& {$[0.26]$} & {$[0.61]$} & {$[0.12]$} & {$[0.54]$} & {$[0.39]$} & {$[0.01]$} & {$[0.03]$} & {$[0.04]$} \\
Gilts 25 years+ & -0.58 & -0.38 & -0.25 & -0.06 & -0.07 & -0.26 & -0.24 & -0.18 \\
& {$[0.04]$} & {$[0.03]$} & {$[0.12]$} & {$[0.54]$} & {$[0.67]$} & {$[0.39]$} & {$[0.21]$} & {$[0.39]$} \\
Effective Exchange Rate & -0.01 & -0.04 & -0.03 & 0.01 & 0.07 & 0.13 & 0.27 & 0.18 \\
& {$[0.39]$} & {$[0.26]$} & {$[0.21]$} & {$[0.39]$} & {$[0.67]$} & {$[0.74]$} & {$[0.88]$} & {$[0.79]$} \\
FTSE 100 & -0.02 & -0.01 & -0.01 & 0.00 & 0.01 & 0.01 & 0.03 & 0.03 \\
& {$[0.09]$} & {$[0.26]$} & {$[0.26]$} & {$[0.88]$} & {$[0.39]$} & {$[0.67]$} & {$[0.74]$} & {$[0.79]$} \\
10 year AAA bonds & -0.09 & -0.06 & -0.05 & 0.01 & 0.01 & -0.02 & -0.04 & -0.05 \\
10 year BBB bonds & {$[0.33]$} & {$[0.39]$} & {$[0.26]$} & {$[0.33]$} & {$[0.33]$} & {$[0.04]$} & {$[0.06]$} & {$[0.01]$} \\
10 year Swap & -0.13 & -0.09 & -0.07 & -0.00 & -0.05 & -0.06 & -0.09 & -0.15 \\
10 Year OIS & {$[0.33]$} & {$[0.54]$} & {$[0.06]$} & {$[0.26]$} & {$[0.91]$} & {$[0.04]$} & {$[0.09]$} & {$[0.33]$} \\
& -0.03 & -0.01 & -0.01 & -0.01 & -0.02 & -0.05 & -0.08 & -0.07 \\
& {$[0.02]$} & {$[0.33]$} & {$[0.21]$} & {$[0.26]$} & {$[0.39]$} & {$[0.06]$} & {$[0.46]$} & {$[0.21]$} \\
& 0.00 & 0.02 & -0.00 & -0.01 & -0.3 & -0.07 & -0.11 & -0.11 \\
& {$[0.16]$} & {$[0.46]$} & {$[0.61]$} & {$[0.67]$} & {$[0.21]$} & {$[0.06]$} & {$[0.21]$} & {$[0.12]$} \\
\hline \hline
\end{tabular}

Note: The table presents average price differential (per cent) between price at end of day of QE operation and price at various horizons. In all cases the asset price is adjusted for any trend over the sample, in most cases through a simple linear trend adjustment, but for APF gilts using the yield curve model. Thus, the first row reproduces the results of the final two rows of table 5. Figures in square brackets represent the probability that the price differential is zero, based on the two-sided Wilcoxon Rank Test. OIS data courtesy of the Bank of England. 
Figure 1

\section{Bank of England's balance sheet}
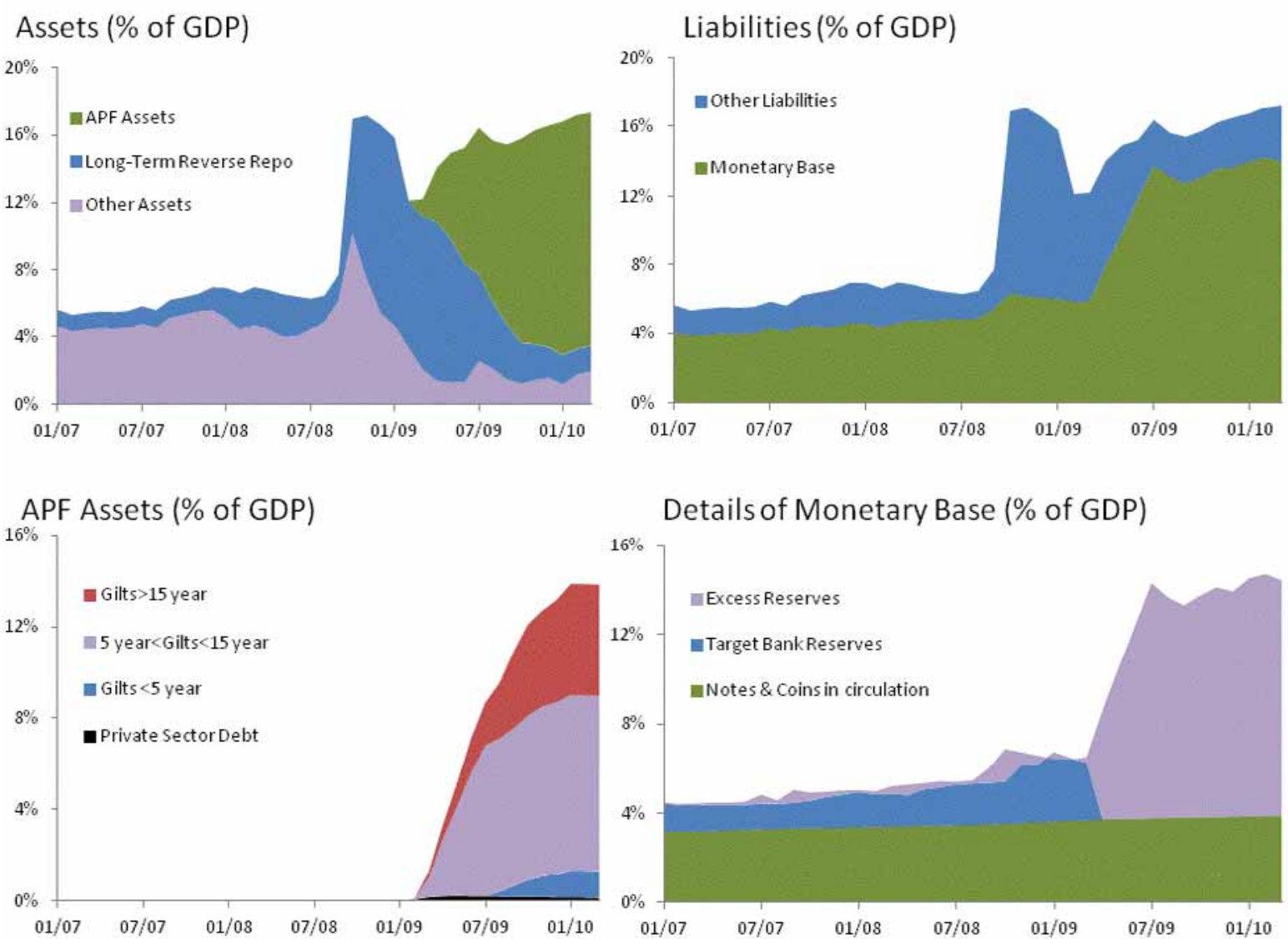

Details of Monetary Base (\% of GDP)

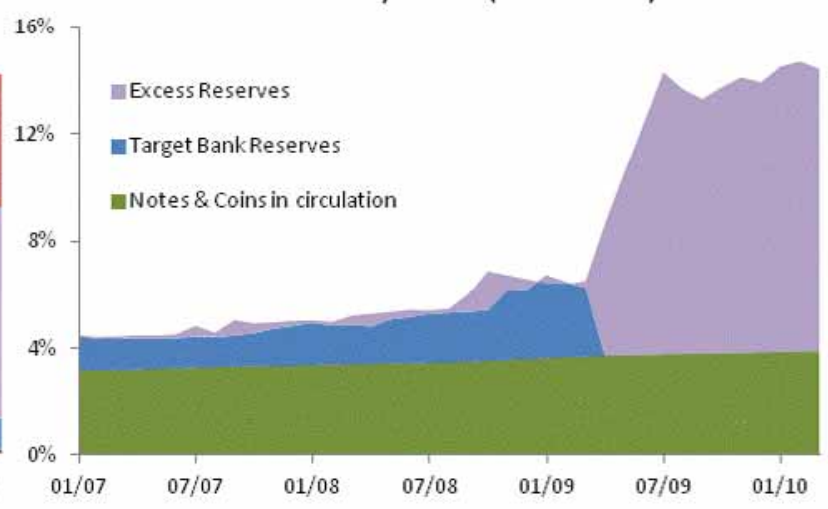


Figure 2

\section{Gilt holdings by sector as a fraction of GDP}

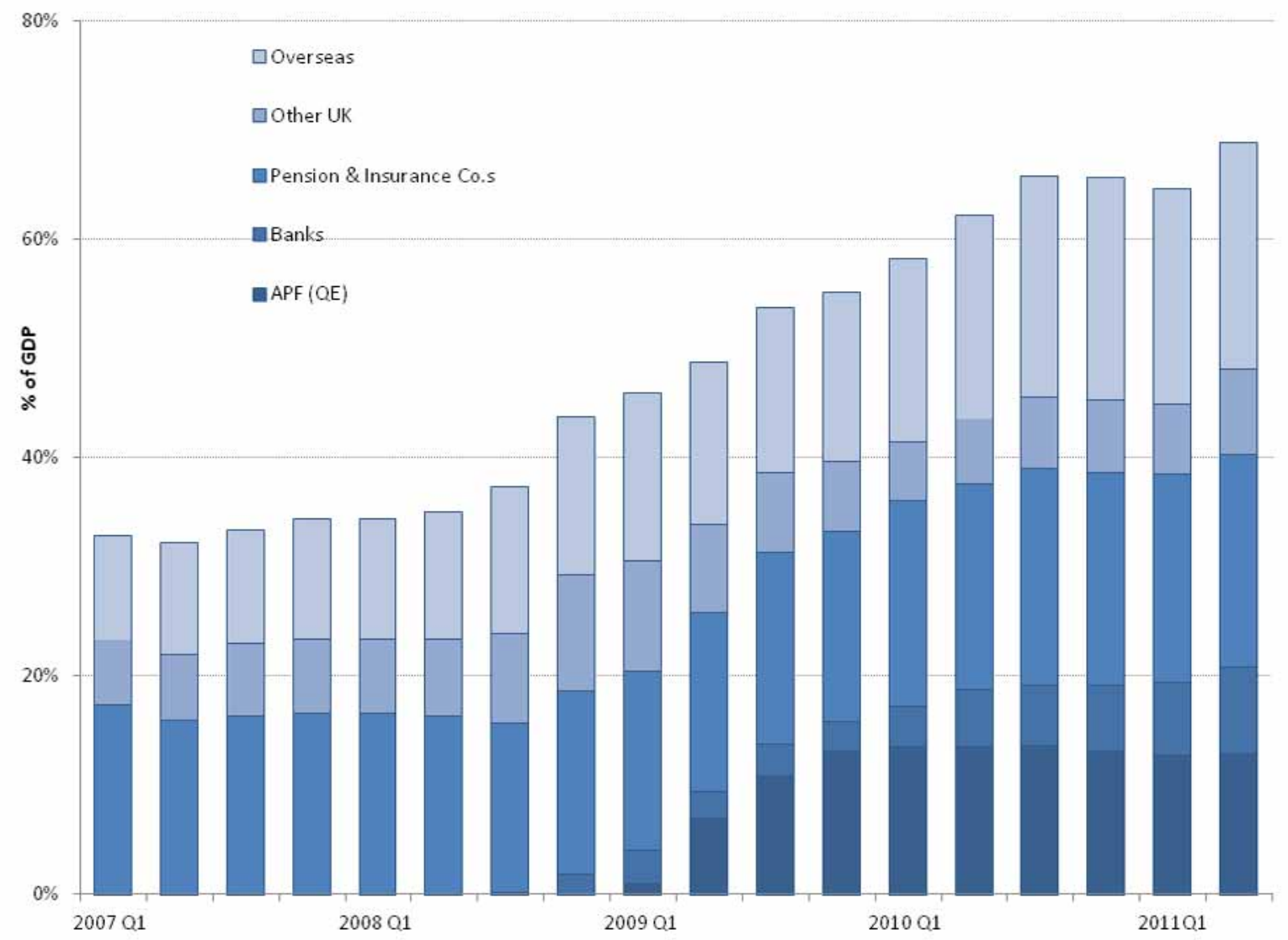


Figure 3

M4X and year-on-year growth of M4X

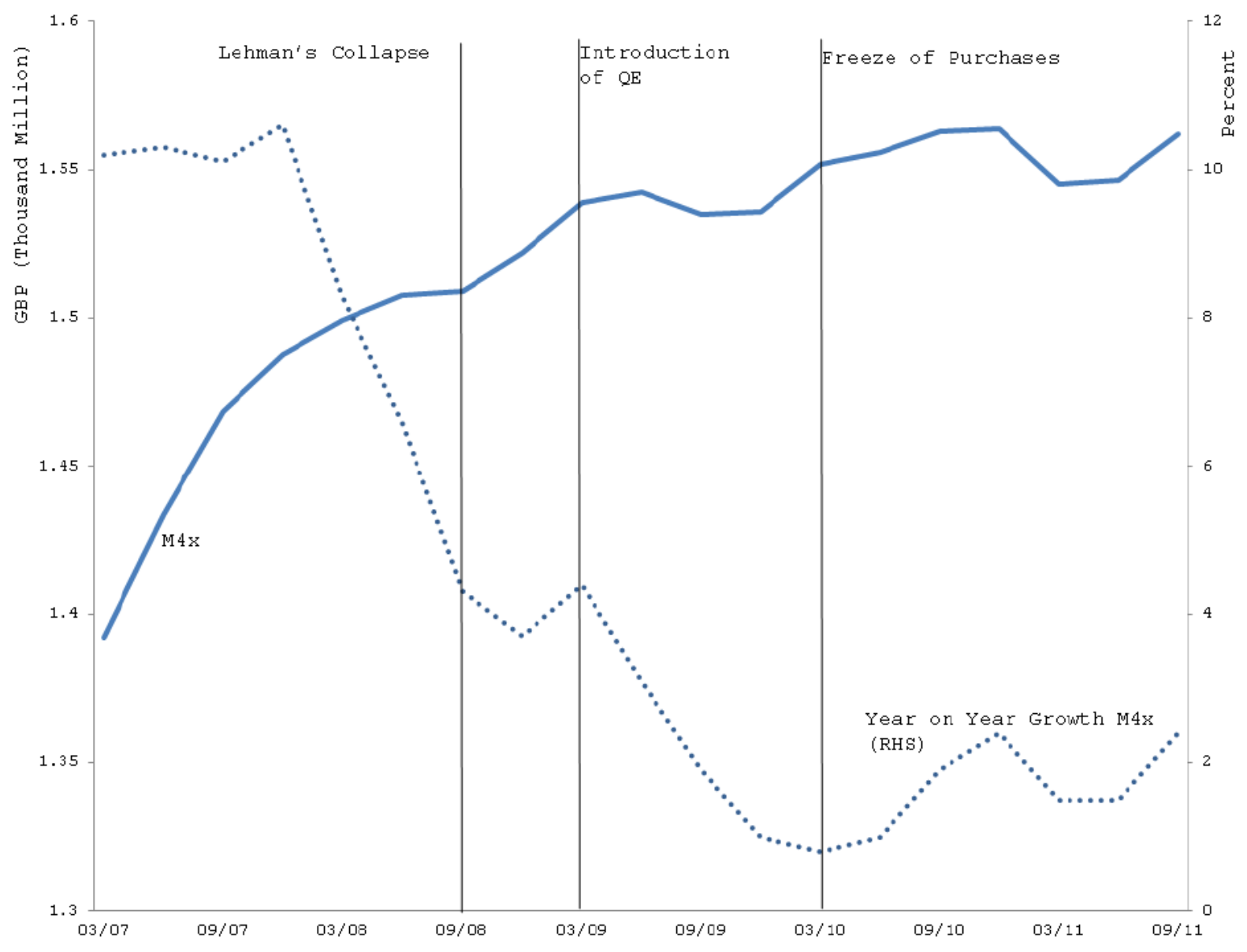


Figure 4

Year-on-year growth in total M4x lending to households and to PNFCs

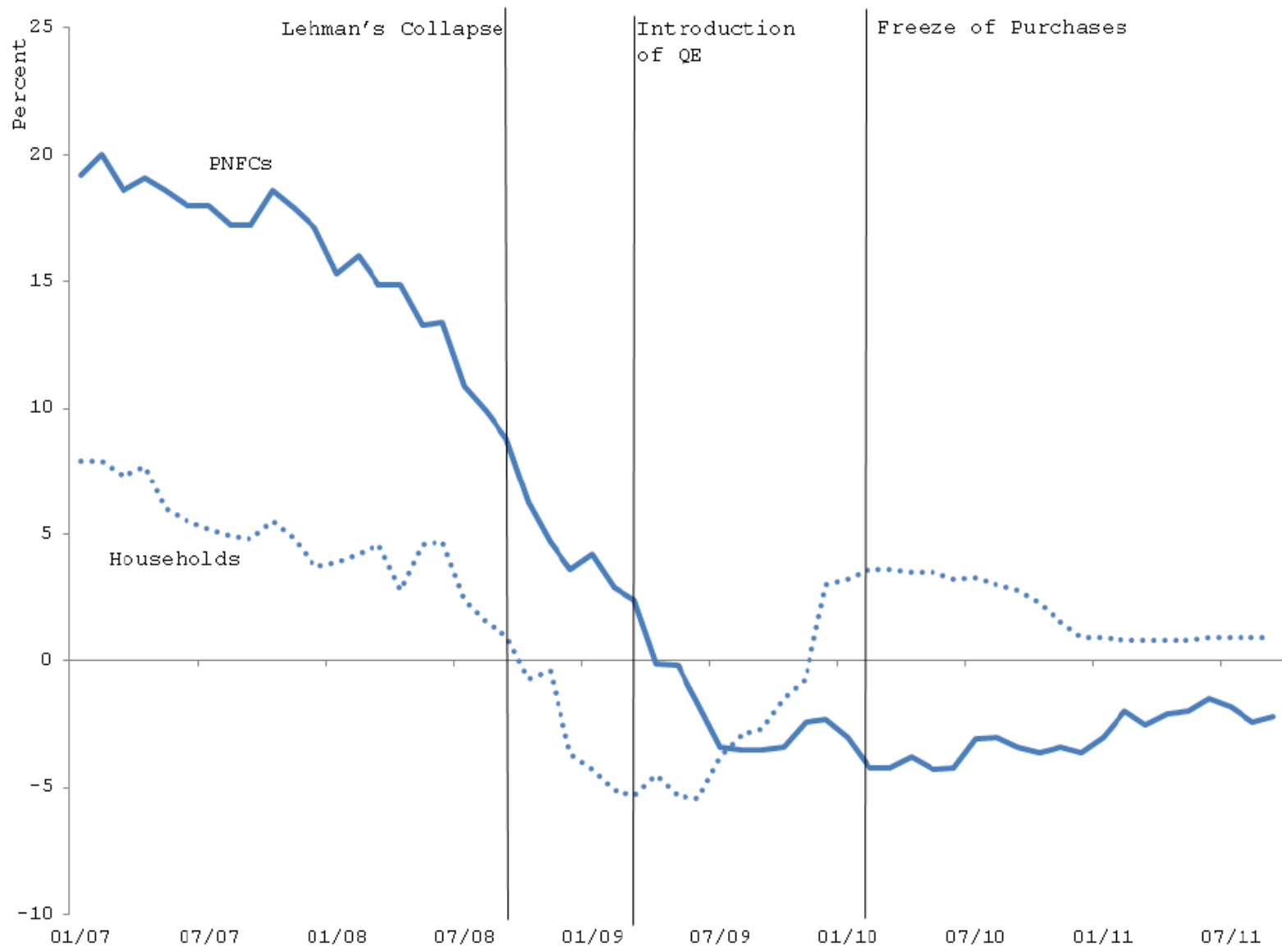


Figure 5

The availability of corporate credit

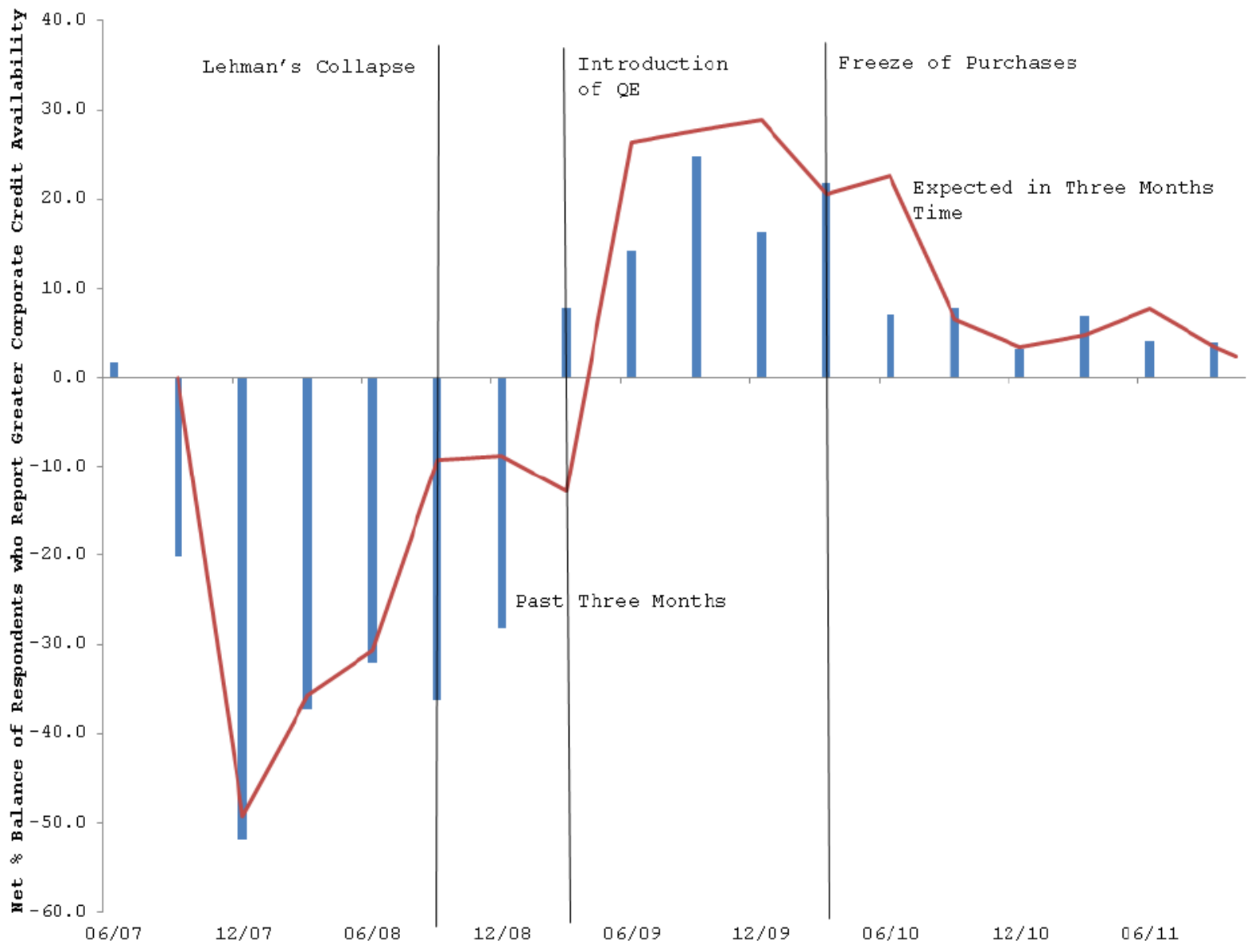


Figure 6

Monthly net capital issuance by sector

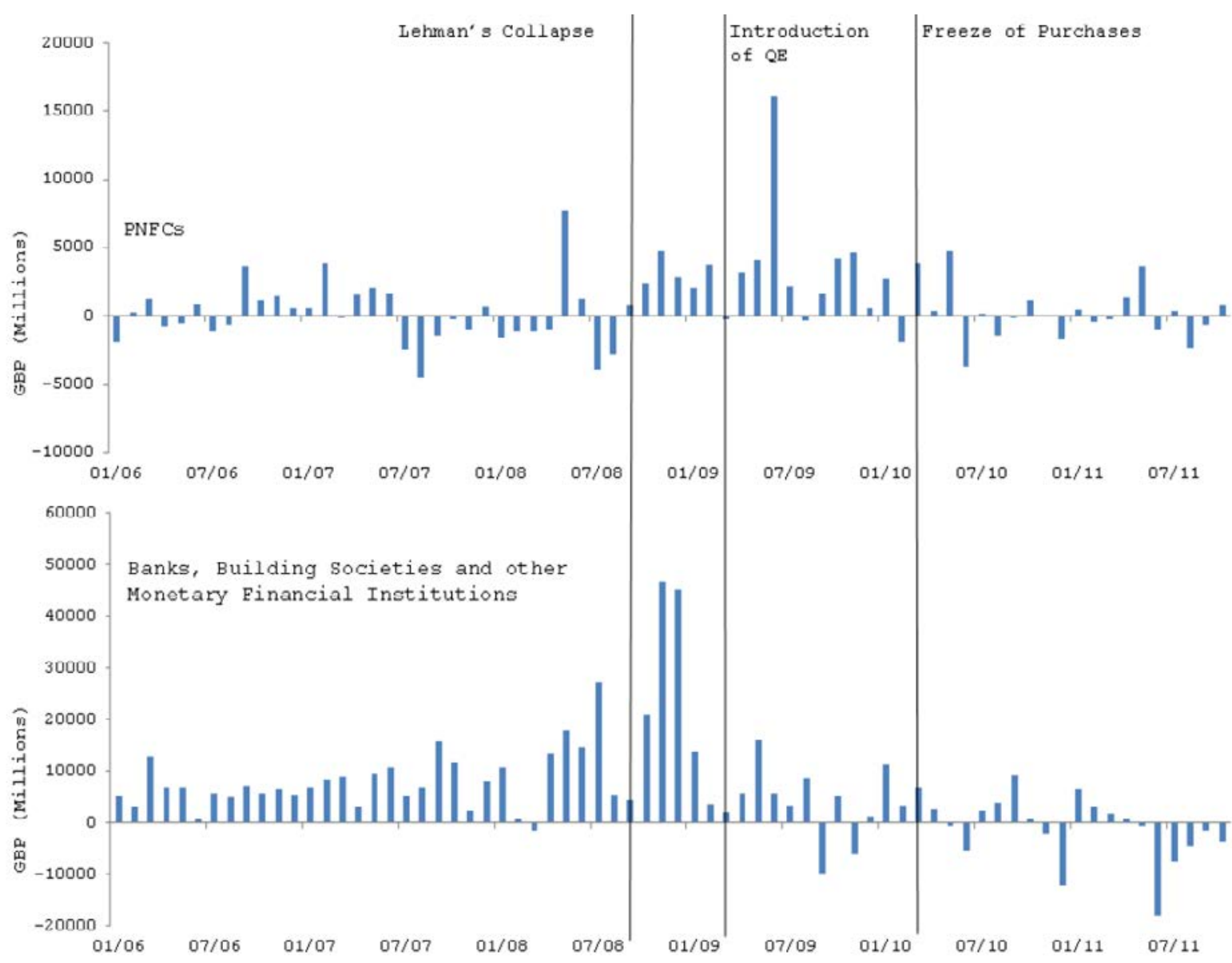

Figure 7

Impulse responses of forward curve to $1 \%$ shock in macro factors
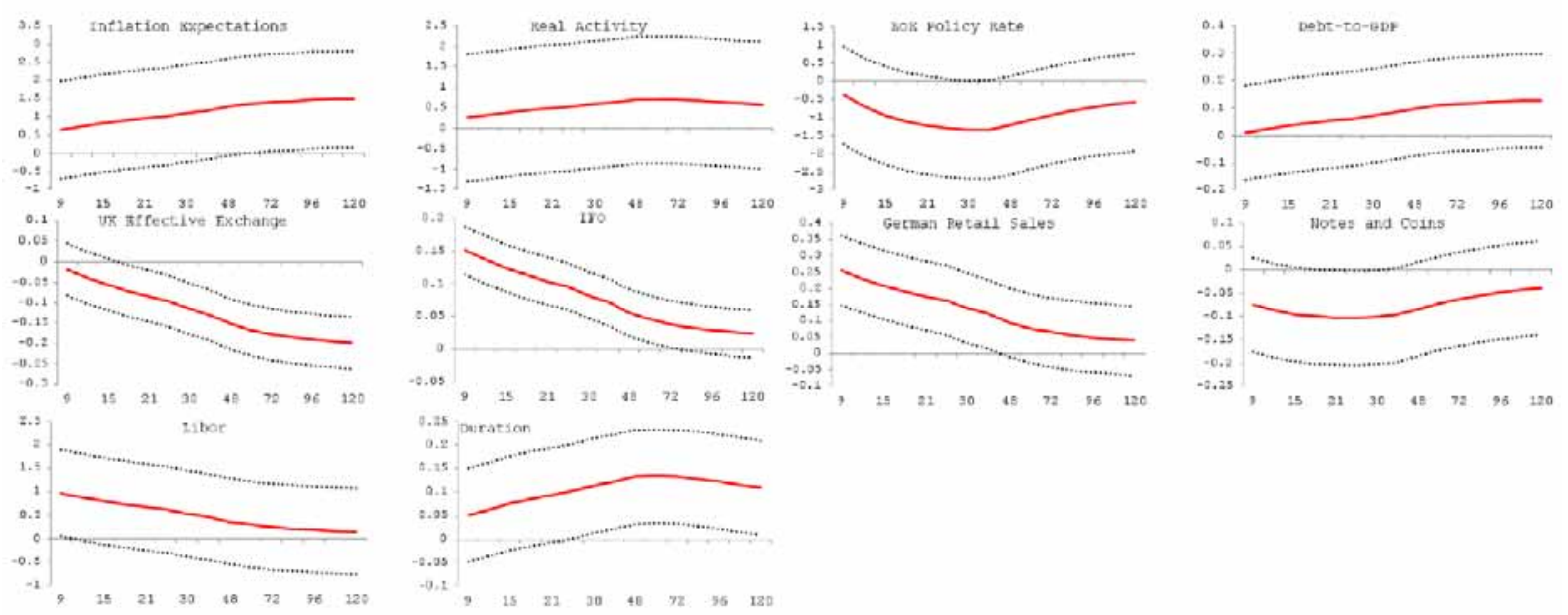
Figure 8

\section{1-, 5- and 10-year actual and forecast forward rates}
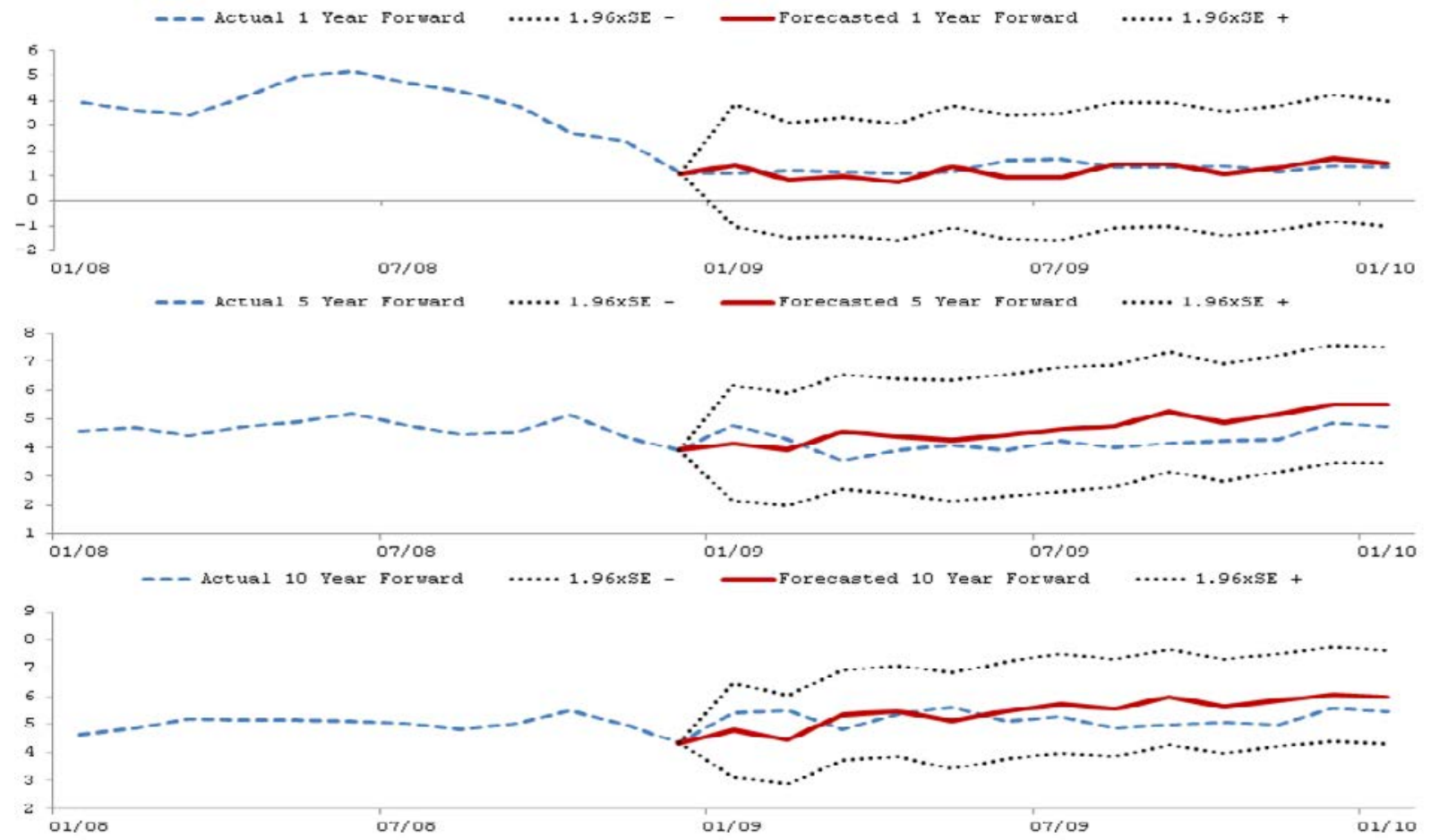

Note: Figure 8 presents the actual forwards from January 2008 to January 2010. We also include the forecast and the forecast interval (95\% confidence). To construct the forecast interval for each forward (1-, 5- and 10-year) we take the forecasted factors from the SUR regression and multiply these estimated factors by the appropriate factor-weighting for each maturity from the Svensson methodology, across each of the forecast periods. We then construct a joint forecast error from each of the different factors for each forecast observation, also multiplying the forecast error by each factor weight so that it is scaled accordingly. 
Figure 9

5- and 10-Year UK government debt credit default swap spreads

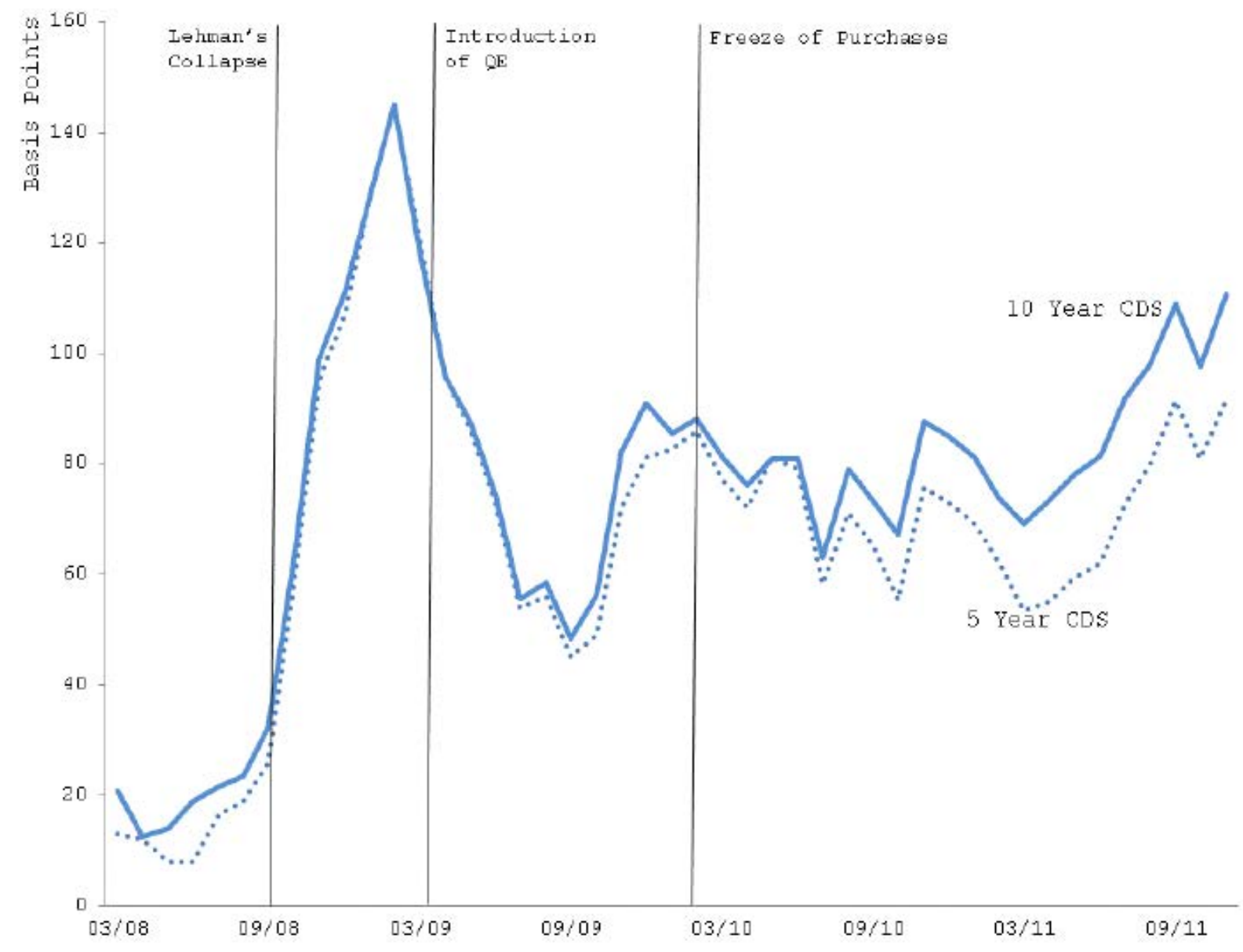


Figure 10

Average price response around QE operations

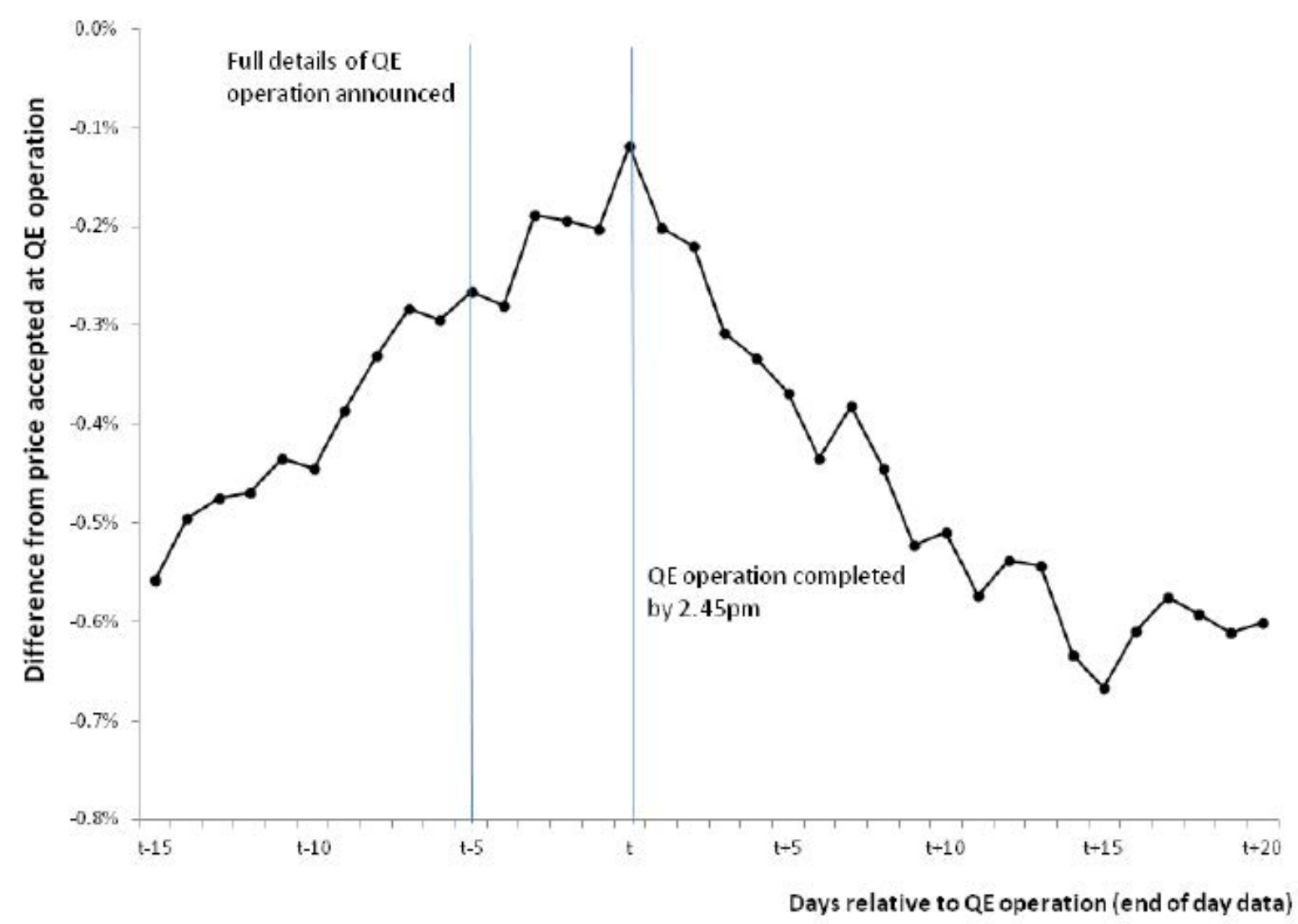




\section{References}

Ahmad, F. and Steeley, J. (2008). "Secondary market pricing behaviour around UK bond auctions". Applied Financial Economics, vol 18, pp 691-699.

Anderson, N. and Sleath, J. (1999). "New Estimates of the UK Real and Nominal Yield Curve". Bank of England Working Paper 126, pp 1-41.

Afonso, A. and Martins, M. (2010). "Level, Slope, Curvature of the Sovereign Yield Curve, and Fiscal Behaviour". ECB Working Paper No 1276, pp1-63.

Beneish, M. and Whaley, R. (1996). "An anatomy of the S\&P Game: The Effect of Changing the Rule". Journal of Finance, vol 51, iss 5, pp 1909-1930.

Bernanke, B., Reinhart, V. and Sack, B. (2004). "Monetary Policy Alternatives at the Zero Bound: An Empirical Assessment". Brookings Papers on Economic Activity, vol 35, iss 2, pp 1-100.

Caglar, E., Chadha, J.S., Meaning, J., Warren, J. and Waters, A. (2011). "Central Bank Balance Sheet Policies: Three Views From the DSGE Literature". Interest Rates, Prices and Liquidity. Cambridge University Press, pp 240-273.

D'Amico, S. and King, T. (2010). "Flow and Stock Effects of Large-Scale Treasury Purchases". Finance and Economics Discussion Series 2010-52, pp 1-41.

Diebold, F., Rudebusch, G. and Aruoba, S. (2006). "The Macroeconomy and the Yield Curve: A Dynamic Latent Factor Approach". Journal of Econometrics, vol 131, pp 309-338.

Doh, T. (2010). "The Efficacy of Large-Scale Asset Purchases at the Zero Lower Bound". Economic Review. Federal Reserve Bank of Kansas City Economic Review, iss 2, pp 5-34.

Financial Times. (2010). "UK Quantitative Easing: Policy-Based Evidence-Making". Money Supply Blog. 4 February.

Gagnon, J., Raskin, M., Remache, J. and Sack, B. (2010). "Large-Scale Asset Purchases by the Federal Reserve: Did They Work?". Economic Policy Review, May iss, pp 41-59.

Hamilton, J.D. and Wu, J. (2010). "The Effectiveness of Alternative Monetary Policy Tools in a Zero Lower Bound Environment". University of California, San Diego. Working Paper. pp 1-75.

Hancock, D. and Passmore, W. (2011). "Did the Federal Reserve's MBS Purchase Program Lower Mortgage Rates?". Finance and Economics Discussion Series 2011-01, pp 1-62.

Hau, H., Massa, M., and Peress, J. (2010). "Do Demand Curves for Currencies Slope Down? Evidence from the MSCI Global Index Change". Review of Financial Studies, vol 23, iss 4, pp 1681-1717.

Joyce, M., Lasaosa, A., Stevens, I. and Tong, M. (2010). "The Financial Market Impact of Quantitative Easing". Bank of England Working Paper No 393, pp 1-44.

Krishnamurthy, A. and Vissing-Jorgensen, A. (2011). "The Effects of Quantitative Easing on Long-term Interest Rate". Northwestern University Working Paper, pp 1-47.

Meier, A. (2009). "Panacea, Curse, or Nonevent: Unconventional Monetary Policy in the United Kingdom". IMF Working Paper No 09/163, pp 1-48.

Modigliani, F. and Sutch, R. (1966). "Innovations in Interest Rate Policy". American Economic Review, vol 52, pp 178-197.

Nath, P. (2004). "Interdealer Trading in the UK Government Bond Market". London Business School Mimeo, pp 1-44.

Neely, C. (2010). "The Large-Scale Asset Purchases Had Large International Effects". Federal Reserve Bank of St. Louis Working Paper 2010-018, pp 1-45. 
Svensson, L. (1994). "Estimating and Interpreting Forward Interest Rates: Sweden 1992 to 1994". NBER Working Paper No. 4871, pp 1-49.

Swanson, E. (2011). "Let's Twist Again: A High-Frequency Event-Study Analysis of Operation Twist and Its Implications for QE2". Brookings Papers on Economic Activity, Spring, pp 151-187.

Ugai, H. (2007). "Effects of the Quantitative Easing Policy: A Survey of Empirical Analyses. Monetary and Economic Studies". Institute for Monetary and Economic Studies, Bank of Japan, vol 25, iss 1, pp 1-48.

Wright, J. (2011). "What does Monetary Policy do to Long-term interest rates at the Zero Lower Bound?". NBER Working Paper 17154, pp1-37. 